\title{
Residual Neuromuscular Blockade in Paediatric Anesthesia: prospective observational trial
}

\author{
Jozef Klučka ${ }^{1}$, Hana Harazim², Ivo Křikava ${ }^{1}$, Martina Kosinová ${ }^{1}$, Roman Štoudek ${ }^{1}$, Petr Štourač ${ }^{1}$, Michaela \\ Ťoukalková ${ }^{1}$, Milan Kratochvíl ${ }^{1}$ and REPEB study group \\ ${ }^{1}$ Department of Paediatric Anaesthesiology and Intensive Care Medicine, Faculty of Medicine, Masaryk \\ University and University Hospital Brno, Czech Republic \\ ${ }^{2}$ Department of Anesthesiology and Intensive Care Medicine, Faculty of Medicine, Masaryk University and \\ University Hospital Brno, Brno, Czech Republic
}

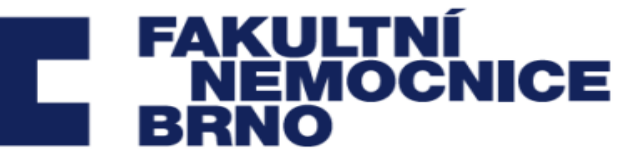
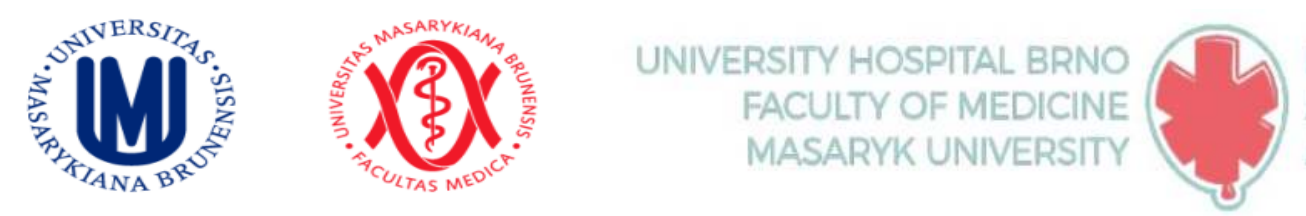

PEPARTMIENT OF PAEDIATRIC ANAESTHIESIOLOCY
AND INTENSIVE CARE MEDICINE

\section{* AKUTNE:CZ}

Background: Residual neuromuscular blockade (RNB) in postoperative period is frequent (26-88\%) and it is associated with negative impact on perioperative morbidity. The safety cut-off measured by accelerometry is currently defined as Train-of-four ratio (TOFr) $\geq 0.9$. The primary outcome of the study was detect the incidence of RNB measured just prior extubation in the operating room (OR) (according to pragmatic trial design) and the secondary outcome was the incidence of the RNB in postanaesthesia care unit (PACU).

Methods: After Ethics Committee (10/2016) approval and trial registration - NCT02939911, www.clinicaltrials.gov, paediatric patients (1.1.2017-31.12.2017) undergoing surgery in general anaesthesia with muscle relaxation were included in the study. The level of blockade was measured just prior to extubation at the OR (patient eligible for extubation according to the anesthesiologist judgement) and after arrival at PACU with accelerometry - TOF-Watch ${ }^{\circledR} S X$ (Organon, Inc, West Orange, NJ, Picture 1.). The mode for measurement was Train-of-four (TOF) and Train-of-four ratio (TOFr), in case of deep blockade Post-tetanic count (PTC). Data are described by descriptive analytic methods (mean, standard deviation $\mathrm{SD}$, median).

Table 1. - Incidence of RNB at OR and PACU

\begin{tabular}{|c|c|c|c|c|c|c|}
\hline & \multicolumn{3}{|c|}{ TOF OR $(n=282)$} & \multicolumn{3}{c|}{ TOF PACU $(n=119)$} \\
\hline & $n$ & $\%$ & $95 \% \mathrm{Cl}$ & $n$ & $\%$ & $95 \% \mathrm{Cl}$ \\
\hline $\begin{array}{c}\text { TOF } \geq \\
0,9\end{array}$ & 146 & $51,8 \%$ & $\begin{array}{c}45,9- \\
57,6 \%\end{array}$ & 87 & $73,1 \%$ & $\begin{array}{c}64,7- \\
80,5 \%\end{array}$ \\
\hline $\begin{array}{c}\text { TOF }< \\
\text { (RNB) }\end{array}$ & 136 & $48,2 \%$ & $\begin{array}{c}42,4- \\
54,1 \%\end{array}$ & 32 & $26,9 \%$ & $\begin{array}{c}19,5- \\
35,3 \%\end{array}$ \\
\hline
\end{tabular}

Results: Overall, 291 patients were included in the study. The incidence of RNB at the OR was $48.2 \%(95 \% \mathrm{Cl}$ : 42.4-54.1\%, $\mathrm{n}=136$ ) and the incidence of RNB in PACU was $26.9 \%(95 \% \mathrm{Cl}$ : 19,5-35,3 \%, $\mathrm{n}=32)$ (Table 1. and Graph 1.). Active reversal of neuromuscular blockade was administered in $23.3 \%(n=68)$ of patients. Overall, $31.6 \%$ (87/275) of patients were extubated with TOFr $<0.9$.

Conclusion: Residual neuromuscular blockade in selected cohort of paediatric patients was frequent.

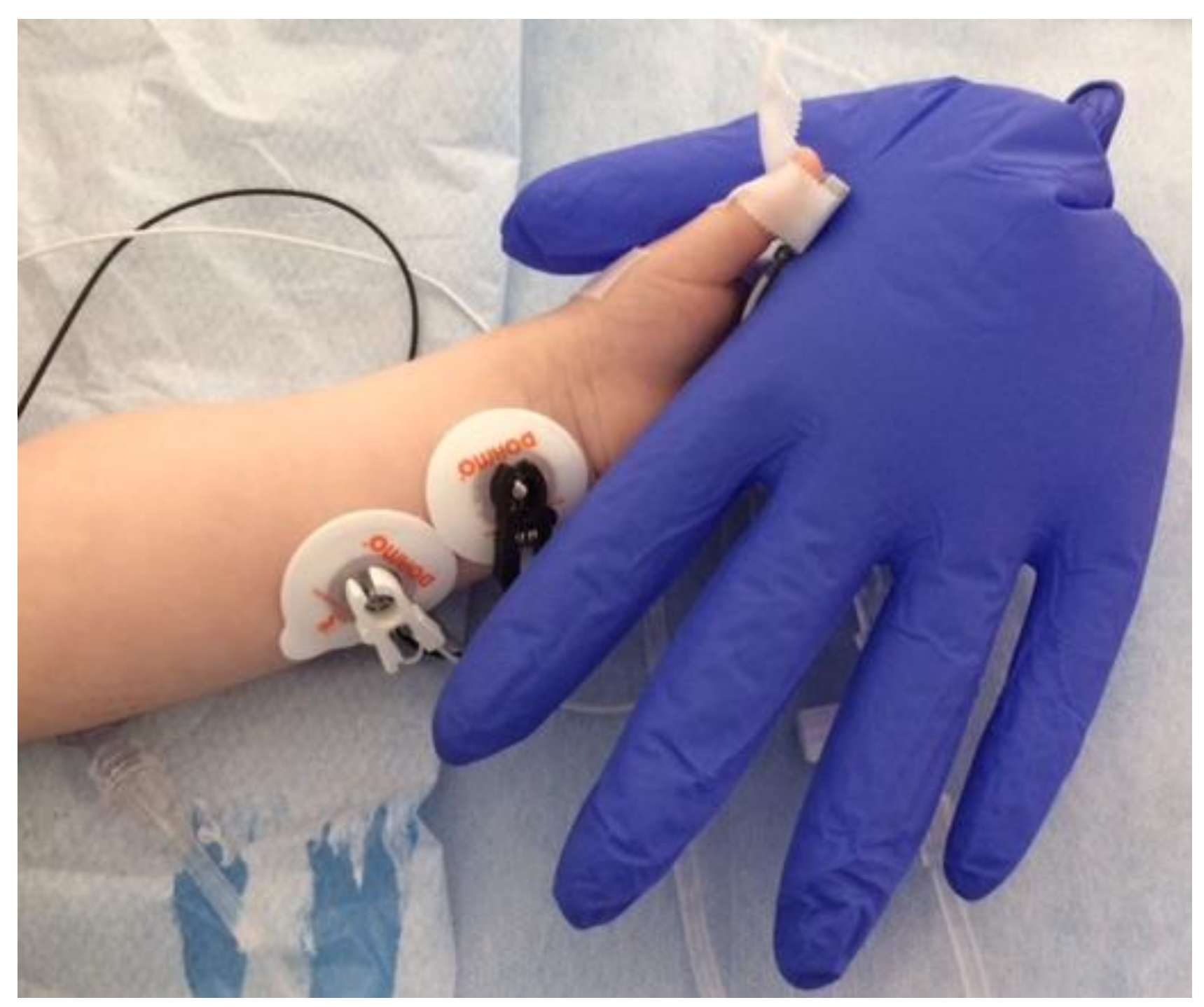

Picture 1. - TOF monitoring - toddler

Graph n.1 Incidence of residual neuromuscular blockade

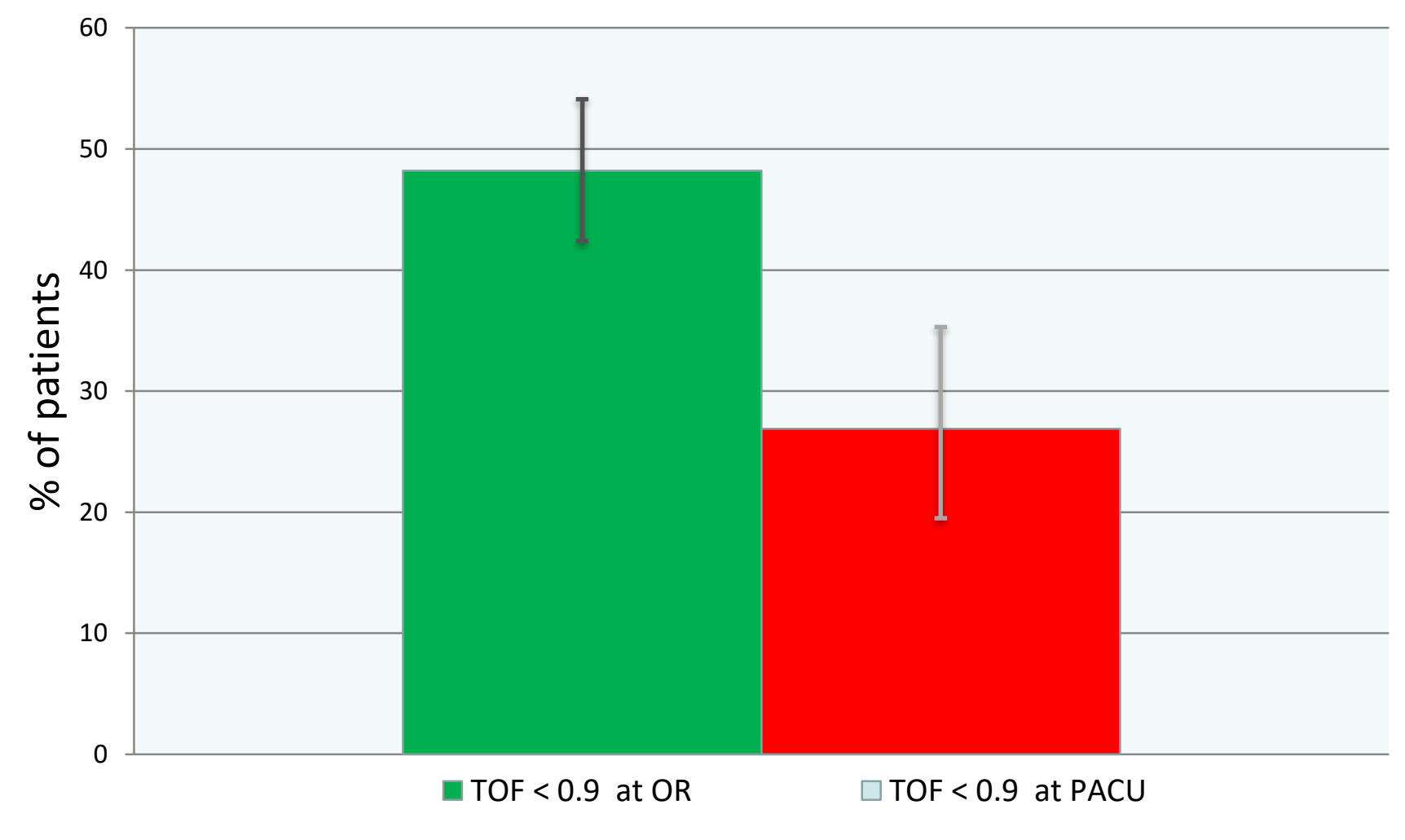

